IRSH 49 (2004), pp. I 32-I4I DOI: I0.10I7/S002085900300I42 I

(C) 2004 Internationaal Instituut voor Sociale Geschiedenis

\title{
Rhetoric, Social History, and Contentious Politics: Reply to Critics
}

\author{
Charles TiLLY
}

Aristotle's vigorous vindication of rhetoric pairs it with dialectic. Dialectic, for Aristotle, combines logical propositions with induction from rigorous evidence in an effort to prove a case beyond doubt. Rhetoric parallels dialectic, but combines arguments with examples in an effort to persuade. Neither one amounts to science, which for Aristotle requires irrefutable establishment of general principles. Aristotelian rhetoric comes in three varieties:

(I) political: arguing for or against a proposed course of action;

(2) forensic: attacking or defending someone;

(3) ceremonial: praising or condemning someone.

In all three varieties, effective rhetoric depends not only on solid logic but also on canny knowledge of human character and emotion. It depends on relations among speaker, arguments, and audience. In the language of Dynamics of Contention (hereafter DOC), ${ }^{\mathrm{I}}$ Aristotle proposed an inescapably relational account of rhetoric. As his discussion drew to a close, Aristotle drew on his knowledge of audiences to offer rhetoricians sage advice:

As to jests. These are supposed to be of some service in controversy. Gorgias said that you should kill your opponents' earnestness with jesting and their jesting with earnestness; in which he was right. Jests have been classified in the Poetics. Some are becoming to a gentleman, others are not; see that you choose such as become you. Irony better befits a gentleman than buffoonery; the ironical man jokes to amuse himself, the buffoon to amuse other people.

The Epilogue has four parts. You must: (I) make the audience welldisposed towards yourself and ill-disposed towards your opponent; (2) magnify or minimize the leading facts; (3) excite the required state of emotion in your hearers; and (4) refresh their memories. ${ }^{2}$

Two conclusions follow directly. First, a rhetorical effort's success

I. Doug McAdam, Sidney Tarrow, and Charles Tilly, Dynamics of Contention (Cambridge, 200I).

2. Aristotle, The Basic Works of Aristotle, Richard McKeon (ed.) (New York, I94I), pp. I449I 450 . 
depends on how well the rhetorician gauges the likely reaction that the audience will give to the combination of speaker and arguments. Second, the same arguments and speakers will have different effects on different audiences.

Aristotle's treatment of rhetoric helps us understand how DOC's authors could appear simultaneously to be pretentious buffoons in the service of American imperialism (Simeon), macrosociologists who hanker after universals but avoid the philosophical difficulties posed by universals (Welskopp), and ambitious social theorists who blur crucial relations and distinctions (Kjeldstadli). For, whatever else it does, DOC adopts political rhetoric in Aristotle's sense: the book argues for a distinctive program of research and explanation in regard to political struggle. Its authors can only hope that Welskopp and Kjeldstadli come closer to the book's main audience than does Simeon.

In the first published statement of their motivating questions, collaborators McAdam, Tarrow, and Tilly (hereafter McTeam) described themselves as:

[...] dismayed by the fragmented subfield structure that has come to characterize the study of contentious politics past and present. This malaise harms younger scholars, who frequently craft dissertations in isolation from others working on related terrain in other disciplines or under the influence of competing paradigms. Accordingly, we hope to survey and synthesize work across the diverse literatures that bear on contentious politics. If we promote conceptual standardization over the field as a whole, so much the better. But we aim chiefly at the identification of causal analogies - discovery that ostensibly disparate political processes actually have similar causal properties. ${ }^{3}$

That early statement announced an explicitly rhetorical aim: to persuade students of political struggle, especially postgraduate students, that they could do better descriptive and explanatory work by attending to causal analogies between the phenomena they were examining and other sorts of contentious politics. We aimed especially at younger students on three grounds: that (as our own experience told us), except in times of widely recognized crisis, older scholars have typically invested so much in established research programs that breaking away costs them considerable effort and self-esteem; that younger scholars are often searching energetically for new programs that will surprise, impress, outwit, or lambaste their seniors; and that we were already actively recruiting Ph.D. students and postdoctoral scholars to the developing DOC program. ${ }^{4}$

Writing five years before DOC, McTeam committed themselves to a fourfold program: (I) mapping the subfields of history, sociology, political

3. Doug McAdam, Sidney Tarrow, and Charles Tilly "To Map Contentious Politics", Mobilization, I (1996), pp. I8-19.

4. For the latter, see McAdam, Tarrow, and Tilly, Dynamics of Contention, Preface. 
science, and economics that actually deal somehow with contentious politics; (2) producing a tentative synthesis of theory and research across those subfields; (3) identifying scope conditions for causal analogies in that synthesis; and (4) considering how forms and dynamics of popular struggle are changing today. While other reports of the program mapped subfields, analyzed contemporary changes in contention, or applied its ideas to particular contentious episodes, DOC itself concentrated on points (2) and (3) - looking for similar causes in diverse settings and forms of contention while also trying to locate limits to those similarities.' It ended up drawing more heavily on geography and anthropology, but less on economics, than the 1996 program statement envisioned. Yet it remained faithful to its vision of helping a new generation open pathways across the encrusted boundaries among ostensibly sui generis forms and sites of contention. It pursued the announced aim of identifying similar causes in diverse genres and settings of politics.

How and how well did the vivifying vision work? DOC's critics divide sharply on that question. Dilip Simeon portrays the book as claiming that: (a) that all of episodic political conflict results from the same giant clockwork; (b) that McTeam have discovered the clockwork's mainsprings, gears, and levers; and (c) that their scheme explains all features of the fifteen contentious episodes on which the book concentrates. The book actually makes no such claims. On the contrary, it states repeatedly - if apparently not frequently or persuasively enough - that a limited number of causal mechanisms appear in a wide variety of contentious episodes, and that those mechanisms help explain some, but by no means all, important similarities and differences among the episodes.

Despite Simeon's allegations, the mechanisms themselves do not resemble those of Newtonian mechanics, but those of contemporary biology. There, analysts have long since rejected interpretations of biota as machines but have persisted in searching for mechanisms - transfers of energy that rearrange relations among stipulated elements. DOC does not require biology as its model or justification. In fact, the search for recurrent causes that concatenate differently with varying large-scale outcomes characterizes many different scientific disciplines, from paleontology to cognitive science to vulcanology. To reject mechanistic explanations of contentious politics ipso facto is to deny that explicable regularities occur in contentious politics.

Simeon wavers between two contradictory positions in this regard. Sometimes he says that social science has no hope whatsoever of explaining complex historical events such as Gandhi's role in the Calcutta of 1946-

5. For other characteristic products, see Ronald Aminzade et al., Silence and Voice in the Study of Contentious Politics (Cambridge, 200I); Jack Goldstone (ed.), States, Parties, and Social Movements (Cambridge, 2003); and Charles Tilly, The Politics of Collective Violence (Cambridge, 2003). 
I 948 or Lenin's in the Russia of I9I7, presumably because such events are either too complicated and individual and/or their true causes remain inaccessible to social science. At other times, however, he grants the existence of a general phenomenon such as nationalism, imputes to DOC the claim to offer a general model of that general phenomenon, then proceeds to trash the imagined general model by naming absent or misstated elements in the DOC explanation.

If the first, we reach an impasse; the disagreement does not then concern particular arguments but their underlying epistemological and ontological assumptions. In that case, Simeon would better serve this journal's readers by laying out his philosophical objections to the whole enterprise of social scientific explanation instead of making DOC the stalking-horse for those objections. If the second, we have some faint hope of continuing the dialogue. In that case, however, Simeon has an obligation to identify the alternative explanations he has in mind - especially since DOC insists that at the level of complex structures and sequences no covering laws are possible.

Thomas Welskopp not only recognizes, but also welcomes, DOC's denial of covering laws for big structures and processes. He remarks rightly that DOC neither faces nor resolves the great questions of historical theory that arise as cultural reductionism loses its charm for historical practice, and as new versions of social history emerge to replace the base-superstructure division inherited from Marxism. ${ }^{6}$ Yet he worries that McTeam are surreptitiously introducing new claims to universality in their search for robust mechanisms. Preferring to ground explanations in theoretical models of society and wishing to retain a distinctive place in explanation for human agency, Welskopp remains suspicious of mechanistic reductionism as a general explanatory strategy.

Welskopp has indeed smoked out explanatory claims that DOC leaves half-hidden. Taken seriously, the appeal to mechanisms implies a kind of determinism: an assumption that every social action or interaction has a cause, that the cause consists of one or more mechanisms, and that in principle (if not in practice) one could construct complete explanations of social processes by tracking down all the various combinations and sequences of mechanisms that cause them. Indeed, within its scope, each mechanism conforms to a small-scale covering law. Properly specified, for example, brokerage always operates in the same way and produces the same immediate effects. Or at least so DOC proposes.

Why, then, did the book make so little of such large claims? Why did

6. Geoff Eley, "Generations of Social History", in Peter N. Stearns (ed.), Encyclopedia of European Social History (New York, 200I), vol. I, pp. 3-30; Charles Tilly, "Neuere angloamerikanische Sozialgeschichte", in Günther Lottes and Joachim Eibach (eds), Kompass der Geschichtswissenschaft (Göttingen, 2002), pp. 38-52. 
DOC omit detailed accounts of its philosophical grounding and implications? The answer goes back to rhetoric, in the Aristotelian sense reviewed earlier. An extended philosophical discussion would have complicated even further an already complex book, and would almost certainly have turned away readers who might disagree with radical mechanistic reductionism but could nevertheless adapt some features of the DOC program to their own ends. My collaborators themselves were less eager than I to adopt an extreme philosophical position, however tentatively.

As written, the book remains compatible with more than one philosophical stance: not only (I) the radical mechanistic reductionism it comes closest to espousing; but also (2) insertion of mechanisms into other explanatory schemes; and (3) forms of historicism, culturalism, and phenomenology that see mechanisms as causes, but argue that they only operate uniformly within strict limits set by their historical, cultural, or phenomenological contexts. That compromise position will not satisfy philosophers of history, but (at least for a while) it facilitates cooperation among theorists and researchers who may eventually part philosophical company.

Welskopp also notes shrewdly that DOC employs two kinds of vocabulary that a strict application of its mechanistic account might seem to forbid: a vocabulary of national politics and a vocabulary of recurrent processes such as nationalism and revolution. Those two self-conscious decisions sprang from rather different rationales. We chose to concentrate explicitly on the national scale as a convenience, not as a claim about the priority of national politics. With so many other comparisons already in play, it would have taxed readers excessively to move repeatedly among politics at different scales and in different sorts of settings. But we did also explicitly propose that similar or identical mechanisms and processes operate at multiple scales from local and intra-organizational to transnational. In order to get the book's main messages across, it seemed - and still seems - sensible to leave part of the new agenda for explication and investigation elsewhere. ${ }^{7}$

What of big words such as nationalism, revolution, democratization, and social movement? DOC actually follows a triple rationale in these regards.

(I) While rejecting visions of these words as representing supra-historical uniformities, the book treats previous analyses of the various phenomena they actually refer to as sources of important questions to which any general treatments of contentious politics must reply: how should

7. See e.g. Doug Imig and Sidney Tarrow, "Studying Contention in an Emerging Polity", in idem (eds), Contentious Europeans: Protest and Politics in an Emerging Polity (Lanham, MD, 200I), pp. 3-26. 
followers of $D O C$ go about describing and explaining the phenomena that previous analysts have called nationalism?

(2) Despite denying that covering laws exist for such complex processes considered as wholes, McTeam concede that within them some smaller scale processes such as polarization and identity shift recur sufficiently often within one or another of them that family resemblances deserve analysis. DOC's chapter 9, for example, challenges any invariant model of democratization, but still claims that similar changes in connections among trust networks, categorical inequality, and public politics underlie most or all instances of democratization.

(3) In fact, the production of widely accepted names for such phenomena affects political realities and provides models for political action; just as to name a series of massacres "genocide" invokes powerful images and possible legal actions, once French political struggles of 1789-1799 acquired the name "revolution," their labeling affected subsequent French politics and suggested models for later dissident actions in France and elsewhere. DOC identifies such labeling processes as a crucial aspect of contentious politics.

Once again, to have devoted precious pages of DOC to spelling out these rationales in detail would have undermined the book's larger rhetorical aim: to provide concrete examples that would invite younger researchers to try the DOC program. As we wrote the book, we discarded extensive discussions of previous literature, of variation in political regimes, of method, and of much more, all in the hope of focusing on the main line of persuasion. The detailed historiographic and philosophic analyses in which Thomas Welskopp and I often engage elsewhere likewise fell by the wayside.

In contrast to Welskopp's search for the book's hidden text and subtext, Knut Kjeldstadli concentrates his attention on how DOC actually presents mechanisms, processes, and episodes. In a phrase I wish we had invented, he nicely characterizes DOC as developing a version of "local causality" in opposition to grand laws of social process. But he criticizes the book for unclear specification of differences and relations among mechanisms, processes, and episodes. Since I wrote most of the book's general discussions concerning mechanisms, processes, and episodes, I bear the largest blame for that rhetorical failure.

Let me plead errors of omission and commission. With respect to episodes, I underestimated the topic's difficulty for readers who were not already analyzing contentious episodes systematically. I have spent much of my career assembling catalogs of contentious episodes, making clear that such episodes were analytic devices rather than natural entities, and warning that all enumerations of episodes depend on complex theories concerning the generation of evidence, theories that require verification in 
their own right. $^{8}$ It therefore seemed sufficient to define contentious episodes as "unique sequences of alterations in relations among connected elements", 9 leaving aside the attendant methodological, epistemological, ontological, and theoretical discussions. Without comment, furthermore, DOC rejected the idea that participants' own definitions of episodes should take priority over analysts' definitions.

Those were sins of omission. They left readers free to suppose that McTeam considered contentious episodes as either natural entities or innocent observational tools. In fact, as Kjeldstadli says at length, analyzing how narratives, explanations, and enumerations of episodes interact presents some of the most complex and interesting problems in work on contentious politics. We were probably right to avoid encumbering $D O C$ 's main text with methodological disquisitions. But in hindsight we probably should have attached a technical appendix expanding the brief practical injunctions of our chapter 3 .

Both omission and commission generated more confusion than necessary on the count of mechanisms and processes. No aspect of DOC has incited more complaints. Some of those complaints (although not, it seems, Kjeldstadli's) stem from discomfort with overtones of the word "mechanism" itself. For all its everyday employment in natural science, the term "mechanism" rarely appears in social-scientific explanations. Its rarity results, I think, partly from the term's disquieting suggestion that social processes operate like clockwork, but mainly from its uneasy coexistence with predominant strategies of explanation in social science: (a) proposal of covering laws for complex structures and processes; (b) the special case of covering law accounts featuring the capacity of predictors within mathematical models to exhaust the variance in a "dependent variable" across some set of differing but comparable cases; (c) specification of necessary and sufficient conditions for concrete instances of the same complex structures and processes; (d) location of structures and processes within larger systems they supposedly serve or express; and/or (e) identification of individual or group dispositions just before the point of action as causes of that action.

Without much self-conscious justification, most social scientists recognize one or another of these - especially individual or group dispositions - as genuine explanations. They grow uneasy when someone identifies mechanisms as explanations. As a practical matter, nevertheless, social scientists often refer to mechanisms as they construct partial explanations of complex structures or processes. Most of the mechanisms

8. See Charles Tilly, The Contentious French (Cambridge, 1986), appendix; idem, Popular Contention in Great Britain (Cambridge, 1995), appendix; idem, "Event Catalogs as Theories", Sociological Theory, 20 (2002), pp. 248-254.

9. McAdam, Tarrow, and Tilly, Dynamics of Contention, p. 85 . 
DOC cites - for example, brokerage, emulation, diffusion, and attribution - figure widely in other people's explanations of contention. The DOC account differs from others chiefly in labeling such causes explicitly as mechanisms and in claiming that concatenated mechanisms by themselves provide valid and verifiable explanations of contentious episodes. Relying on the precedents of Robert Merton, Arthur Stinchcombe, and others, ${ }^{10}$ we assumed greater comfort with mechanistic modes of explanation in our audience than turned out to be justified.

Following from that overconfidence, individual chapters of $D O C$ proliferated mechanisms ad hoc without limiting their numbers, codifying their definitions, schematizing their relations across the book as a whole, or providing a justification of their selection over other known mechanisms which the book did not mention. As we finished writing, to be sure, we noticed the book's unruly array of mechanisms. We comforted ourselves with the thought that it was enough for one book to show that mechanisms helped explain diverse episodes, without claiming for a moment that we had identified a master list of mechanisms spanning all of contentious politics. Alas, we should have issued a more strident warning.

The distinction and relation between mechanisms and processes also caused more trouble than necessary. ${ }^{\text {II }}$ DOC presented two different arguments about processes without sufficiently distinguishing and relating them:

(I) Analysts can decompose contentious episodes into component processes, then explain selected processes within episodes by tracing initial conditions, mechanisms, and their concatenation.

(2) Mechanisms concatenate into processes, which are sometimes (but only sometimes!) robust in the sense that they occur with similar sequences and combinations of mechanisms and with similar overall outcomes.

Although the two arguments are logically compatible, DOC could have saved a good deal of confusion by emphasizing that most processes do not qualify as robust in this sense. Very tentatively, as Kjeldstadli indicates, the book identifies some likely candidates for robust processes: identity shift, elite defection, cross-class coalition formation, and the like. The craft of explanation, in this view, consists of identifying robust processes when they do occur, but mostly of singling out distinctive features of episodes and determining the combinations and/or sequences of mechanisms that cause those features. The strategy of paired comparison around which

I0. Ibid., pp. 24-25.

I I. Charles Tilly, "Mechanisms in Political Processes", Annual Review of Political Science, 4 (200I), pp. 2I-4I; idem, "Historical Analysis of Political Processes", in Jonathan H. Turner (ed.), Handbook of Sociological Theory (New York, 200I), pp. 567-588. 
McTeam organize most of the book follows directly from that understanding of the craft. ${ }^{12}$ But DOC has left the identification and verification of robust processes mainly for future inquiry.

In doing so, $D O C$ has failed to state an elementary principle that seems obvious in retrospect: as such, mechanisms and processes do not exist in nature; identification of mechanisms and processes always remains relative to the current level of observation. How will we then know mechanisms when we see them? We choose a level of observation: individual thoughts, individual actions, social interactions, clusters of interactions, durable social ties, or something else. In the DOC program, the recommended level of observation is the episode - which can by definition vary from small to large, short to long, simple to complex. At that level of observation, we recognize as robust social mechanisms those events that:

(a) involve indistinguishably similar transfers of energy among stipulated social elements;

(b) produce indistinguishably similar rearrangements of those social elements; and,

(c) do so across a wide range of circumstances.

The "elements" in question may be persons, but they also include aspects of persons (e.g. their jobs), recurrent actions of persons (e.g. their amusements), transactions among persons (e.g. Internet communications between colleagues), and configurations of interaction among persons (e.g. shifting networks of friendship). For economy's sake, we can call all of these "social sites". Social mechanisms divide roughly into cognitive, environmental, and relational events - those centering on individual or collective perceptions; those centering on interactions between social sites and their physical settings; those centering on connections among social sites. DOC features relational mechanisms, gives secondary attention to cognitive mechanisms, and (as Kjeldstadli remarks) generally neglects environmental mechanisms despite their prominence in other aspects of McTeam's work.

Social mechanisms concatenate into processes displaying recognizable internal similarities but capable of producing variable overall outcomes depending on initial conditions, sequences, and combinations of mechanisms. Stepping up the level of magnification, to be sure, we can always find more microscopic mechanisms within any given mechanism. Looking within certification (validation of actors, their performances, and their claims by external authorities), for example, we will surely find distinguishable mechanisms of monitoring, negotiation, and communication. Identification of robust mechanisms necessarily remains relative to the current level of observation. At that level, robust mechanisms are

I 2. McAdam, Tarrow, and Tilly, Dynamics of Contention, pp. 8 I -83. 
indistinguishable in their operations and effects across a wide range of circumstances. DOC calls for students of contentious politics to invest major efforts in the identification of robust mechanisms, advocating paired comparison of episodes as a procedure for starting that strenuous but rewarding effort.

Seen as a rhetorical effort, Dynamics of Contention will succeed to the extent that a cohort of younger scholars takes up its challenges. For some, that will mean identifying fruitful causal analogies across ostensibly disparate forms and settings of political contention. For others, it will involve pursuing particular mechanisms such as brokerage or identity shift both inside and outside of contentious politics. Still others, we can hope, will clarify the philosophical foundations of mechanistic explanation, explore how names and models for such phenomena as revolutions and genocide emerge and produce their effects, determine whether similar mechanisms operate at local, national, and transnational scales, develop superior methods for enumerating contentious episodes. systematize the identification and verification of robust mechanisms, and work seriously on how initial conditions, sequences of mechanisms, and combinations of mechanisms interact in the formation of robust processes. If some of these things occur, Dynamics of Contention will soon become obsolete except as a reminder of an effective rhetorical intervention.

This essay, to be sure, addresses a somewhat different audience: social historians young and old, whether or not they specialize in contentious politics. It will accomplish its Aristotelian rhetorical objectives if a few social historians in search of superior explanations set aside the doubts raised by critics Simeon, Welskopp, and Kjeldstadli to learn for themselves whether the DOC program might, indeed, help them do their own work. 